Portland State University

PDXScholar

$11-14-2017$

\title{
Nonverbal Communication in Business Setting Between Japan and the U.S.
}

Chi Dao Ozawa

Portland State University

Follow this and additional works at: https://pdxscholar.library.pdx.edu/honorstheses Let us know how access to this document benefits you.

\section{Recommended Citation}

Ozawa, Chi Dao, "Nonverbal Communication in Business Setting Between Japan and the U.S." (2017). University Honors Theses. Paper 489.

https://doi.org/10.15760/honors.492

This Thesis is brought to you for free and open access. It has been accepted for inclusion in University Honors Theses by an authorized administrator of PDXScholar. Please contact us if we can make this document more accessible: pdxscholar@pdx.edu. 
Nonverbal Communication in Business Setting Between Japan and the U.S.

\author{
By \\ Chi Dao Ozawa \\ An undergraduate honors thesis submitted in partial fulfillment of the \\ Requirement for the degree of \\ Bachelor of Arts \\ In \\ University Honors \\ And \\ International Studies
}

Thesis Advisor

Kenneth Bagley

Portland State University

2017 


\begin{abstract}
As an increasing number of people travel overseas each year for tourism or business, they are likely to be involved in some form of communication with people of different languages and cultural backgrounds. In such situations, Americans often experience difficulty in communicating with non-Americans because of language barrier as well as cultural differences. In addition to language and culture differences, one aspect of intercultural communication that is often overlooked and yet vitally important is the role of nonverbal factors plays in achieving effective communication.

The purpose of this study is, first, to learn the importance of nonverbal communication and what factors that are likely to affect the course of effective and successful communication with people of different cultures. Second, this study focuses on the effect of such nonverbal factors that are present and likely to affect the communication process in the business setting between American and Japanese business people. The implication of this study is that it is important to know the different non-verbal communication factors that are present in the business setting between Japan and the U.S. in order to achieve sufficient communication in intercultural business setting.
\end{abstract}




\section{Introduction}

We are generally aware that nonverbal communication elements affect communication process between people in many ways. On the other hand, most people do not pay attention to nonverbal factors such as gestures, body movements, facial expressions, etc. Nonverbal communication may support and enhance the message, or sometimes contradict it. Realizing this is a distinct possibility; I believe it is vital for us to learn more about nonverbal elements and how they affect the communication between and among people.

I have spent about six years in the U.S. including one year that I spent in Japan studying on a study abroad program. Since then I've become intrigued by some cultural differences and how they affect the intercultural communication process, namely nonverbal cues. Japan and the U.S. have many distinctive cultural differences, most fundamentally collectivism or group orientation for Japanese versus individualism for Americans. I have realized that this basic difference tends to make Americans more expressive and Japanese less expressive in a corresponding process. On the other hand, Japanese people tend to rely more on nonverbal cues. This experience of mine has motivated me to do my senior honors thesis about nonverbal communication involving these two countries. Further, in order to limit my research, I have decided to focus on the effects of nonverbal communication in business settings. According to many researchers, $93 \%$ of all communication is nonverbal $55 \%$ comes from body language and $38 \%$ from tone of voice; therefore, nonverbal communication is immensely important in many daily life situations.

My research question is: What are the differences in nonverbal communication between the U.S. and Japan in business setting and how cultural differences affect nonverbal communication aspects between the two countries? My whole paper will focus on how the nonverbal factors of the U.S. and Japan will affect the communication in business settings. 
Such nonverbal factors may influence a business transaction in a positive way or sometimes in a negative way. I have read some interesting articles regarding some culture differences between the U.S. and Japan and how they affect intercultural communication aspects. In this paper, I will define nonverbal communication as facial expressions, body movement, spatial relationships, visual cues, vocal cues, and social relationship. I will answer my research question by using two main methods: an in-depth literature review and a survey interview. My goal is to examine how these nonverbal factors between the two countries change the intercultural communication aspects in business settings in order to minimize misunderstanding as well as promote communication efficiency.

\section{Literature review}

Potoker talks about the application of selective nonverbal communication strategies for management and training development efforts within diverse cultural environments. She also mentions the "Kouhai" and "Senpai" relationship among Japanese which is the fictive kinship relationships that entail obligations, and status hierarchy--e.g., teacher-student, master apprentice, parent-child, supervisor-employee, etc. This distinction is widely recognized and practiced in Japanese society.

In "Nonverbal Communication in Business: Principles and Applications," Beebe gives a clear definition of nonverbal communication, and then explains how nonverbal messages affect businesses and organizations. He also identifies the specific factors that affect nonverbal communication and offers a few brief suggestions for interpreting nonverbal factors. Further, he states that nonverbal communication research can apply to the personal interview, the group discussion, and conference settings. He stresses that "Nonverbal cues are so important to the communication process that when there is a contradiction between the verbal message and the nonverbal message, we are more inclined to believe the nonverbal message than the spoken or written message" (p.5) He shows 
examples of various types of nonverbal factors that tend to impact small business settings including seating arrangements, the environment, decors and eyes contact.

Another source used for my research comes from "Specific Role of Nonverbal Communication in Business" by Maria Blahova. In this article, the author gives details about nonverbal communication in a business setting through eye contact and body language.. This article is important to my research because it provides some definitions of nonverbal communication, types of nonverbal cues, and the ideal of intercultural interactions.

In addition to these articles, I have found a video called "Japanese Nonverbal Communication" created by Thomas L. Seamster and Camilla Harshbarge. This video shows nonverbal communication in different situations, especially in business setting. In this video, when two Japanese business people meet, they start in a formal way with the exchanging of "meishi" or business cards. The visitor usually is the one to present the "meishi" first. The buyer asks the seller (the visitor) to sit down straight across from him. The exchange in reading of "meishi" in Japanese business interactions shows one's place of employment. Identification with a large and successful firm performs a most prestigious social status. When the secretary serves the guest coffee first and the buyer waits until the guest takes his first drink. The interaction ends with a formal bow. This video is important to my research because it shows that the difference in culture has significant effects on one's behavior. For instance, in the U.S. people don't bow, but instead they shake hands. On the other hand, when President Obama visited Japan in July, 2016, the Japanese prime minister, instead of bowing down, shook President Obama's hand. It shows that they shift their traditional ways in order to fit in with the international ways.

According to Matsumoto in "The Unspoken Way - Haragei: Silence in Japanese Business and Society," all of life strategies imply and are supported on a foundation of unwritten, taken-for-granted rules and assumptions. The key to success is to understand the 
idea of Haragei, means the art of practice of using hara (literally means stomach), this is a concept that endeavors to explore. It refers, in one simple sense, to a visceral communication among Japanese that defies Western logic. According to the author, the Japanese society in Western people's eyes is a cohesive, close knit society, by that it means that if you can't feel haragei or if you can't understand their unspoken language and act in an appropriate way, it proves you're gaijin (non-Japanese). This book is significant to my research because the author shows different ways in communicating in different situations. In this article, the author provides effective and easy-to-understand graphs about how business people in Japan use haragei in exchanging business with their partners.

\section{Description of data}

In order to answer my research question, I conducted a survey about the different nonverbal cues in the U.S. and Japan. My survey contains the following questions:

1. Is there a distinctive relationship between people in higher rank in comparison to those in lower rank (sempai and kouhai in Japanese society)? Are there differences in behavior between superiors and subordinate? If so, how important is such distinction? Why is the senpai-kouhai relationship (a vertical relationship between superior and subordinate) important in business settings?

2. How will attire worn by business partners affect the discussion in the business setting?

3. What kind of behavior is expected when business partners meet for the first time?

4. How do business partners sit, stand, and drink in front of each other?

5. Where are some common places for a business meeting?

6. Are there differences in men and women's behaviors in a business meeting? If there is, how do you explain such behavior?

7. How do business partners exchange business cards? 
8. How far do business partners stand or sit in front of each other?

I sent these questions to 10 Japanese subjects in Japan this summer whom I happen to know as friends or acquaintances. Some of them did job hunting in Tokyo in recent months. Job-hunting in Japan among college students usually begin in their third year of school. They start attending information sessions and applying to companies in order to have a career after graduation. They typically attend many different interviews offered by multiples of companies, and they hope to be accepted by a company of their choice. I also asked some other friends who are already working in companies. These 10 subjects responded to the above survey questions. In addition to the aforementioned survey, I also asked five senior students at PSU who had already experienced job interviews as well as five others who were already working in different job fields.

The results of the survey have helped me to understand some different nonverbal communication factors affecting the business setting in the U.S. A chart below shows the results of the above survey.

\section{Comparative Results}

\begin{tabular}{|c|c|c|}
\hline Questions & United State & Japan \\
\hline 1 & $\begin{array}{l}\text { not too important (as long as } \\
\text { you treat them with respect) }\end{array}$ & extremely important \\
\hline 2 & As neat and nice as you can & $\begin{array}{l}\text { male: strictly black suits and simple decorated ties } \\
\text { Female: Black lady suits and dressed pants or above } \\
\text { the knees skirt }\end{array}$ \\
\hline 3 & $\begin{array}{l}\text { Greetings, firm handshake and } \\
\text { good eye contact }\end{array}$ & Greetings, bowing or handshake and eye contact \\
\hline 4 & $\begin{array}{l}\text { Face to face with the table in } \\
\text { between. Talk slowly and } \\
\text { clearly. Drink when the } \\
\text { partner drink. Nod your head } \\
\text { to show that you are paying } \\
\text { attention. }\end{array}$ & $\begin{array}{l}\text { Face to face with the table in between, ones with } \\
\text { higher ranks seat further from the door and ones with } \\
\text { lower rank sit closer to the doors. Talk clearly, } \\
\text { always look at them in the eyes and nod your head to } \\
\text { show that you are listening and paying attention. Use } \\
\text { echo responses like: e } \sim, \text { hmm } \sim \text {, etc... }\end{array}$ \\
\hline
\end{tabular}




\begin{tabular}{|c|c|c|}
\hline 5 & $\begin{array}{l}\text { Depend if the meeting is } \\
\text { formal or not. Usually in a } \\
\text { restaurant if it's not too } \\
\text { formal. In the office for more } \\
\text { formal meetings. }\end{array}$ & $\begin{array}{l}\text { Mainly in offices but can be negotiable according to } \\
\text { the formalities of the meetings. (sometimes coffee } \\
\text { shops or privately reserved restaurants) }\end{array}$ \\
\hline 6 & No difference & No difference \\
\hline 7 & Just hand it to them & $\begin{array}{l}\text { Hand your business card while reading your name } \\
\text { loudly and clearly. Receive it with both hands. } \\
\text { Placed the cards on the table accordingly to their } \\
\text { ranks. After the meeting put it in the card holder. }\end{array}$ \\
\hline 8 & An armed length & Face to face with a table in between \\
\hline
\end{tabular}

\section{Analysis}

All the responses to the first question I received from American businessmen and women are similar; majority of them think that there is no distinctive relationship between people with higher ranks and people with lower ranks in the U.S. As long as you treat them with respect and politeness then it should be fine. Most of them believe the business works better if they have an equal relationship rather than hierarchical ones. On the other hands, the responses from the Japanese side show distinctly different results. According to the Japanese respondents, this kind of behaviors are important in business settings because East Asian cultures such as Japan have a well-defined hierarchy in social relationships, where respect given to seniority in age and social rank is highly emphasized especially in business settings. This type of hierarchical relationship in business settings means interactions are played out around how the kouhai respects the senpai, and thus understanding and observing this distinction plays a vital role in a successful business transaction. A kouhai can network and build relationships with those of higher rank and age by exhibiting proper communication and behaviors with senpais. Understanding and exhibiting this behavior gives an advantage in having more job opportunities and building relationships with future bosses and colleagues. 
As a senpai, this relationship helps him or her to see who has the interpersonal skills to network with their superiors and give insight to their abilities when working in a company.

The senpai-kouhai relationship in the literature review and in my survey shows how social hierarchy plays an important role in Japanese culture. Matsumoto states that though the majority of the time it is understood to respect and follow the orders of your elders, it is mandatory in a workplace to follow the orders given by those of a higher rank. (Matsumoto, 1988) Distribution of power is seen through these relationships as kouhai must always follow the orders of their senpai. The kouhai is usually left with the most work to do, while the

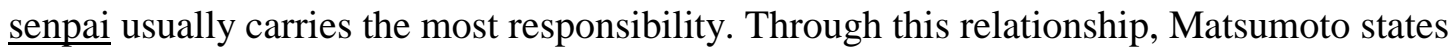
that the kouhai working under the senpai can learn or be protected. It is culturally expected that younger employees obey and listen to what elders say. However, there are a lot of power harassments such as making younger eat a lot (way more than their capacity), drink a lot in the company parties, etc. In meetings where there are older people an atmosphere prevails where it is more difficult for younger ones to say their opinion. This, according to Matsumoto, is called "Dango", which is an everyone-must-be-happy game. The rules for the game are: to respect authority (sempai or high rank people) and tradition, be quiet and have hara (intuition). According to Matsumoto, this is the game that the Japanese have never asked Americans to play. When Dango is taking place, there is no room for substantive discussion and much less clashes of arguments. (Matsumoto, 1988) This kind of human and orderly relation in Japan, according to Kobayashi, is considered inherent and not to be questioned. (Kobayashi, 2016) The payment and promotion system is also based on age and how long the person has been working for the company and not so much on the skills, qualification and contribution that employees bring to the company.

The phrase "judging a book by its cover" is often taught to not adhere by, but due to the nature of human interactions, looks are often the first thing people notice. In business 
settings particularly, the phrase "dress for success" comes in handy. How you dress can give the impression to others that you are also tidy, competent, and organized in the way that you work. In the same token, if you are dressed in wrinkly clothes or with a stain or with unkempt hair, you are likely to give a negative impression that you may not be diligent and organized. First impressions can be powerful in that they may set the standard for how your bosses, or future bosses, see you and carry that image of you. In most cases, the business attire requirements are much stricter in Japanese business meetings. The majority of the answers I received from Japan pointed to dark colored suits and simple-non flashy tie. For ladies, they need to wear formal suit-top, a dressed pants or a knee-high skirt.

According to Ravi S. Kudesia and Hillary Anger Elfenbein, "elements of physical appearance such as facial structure, attractiveness, and height are largely determined by genetic components and early exposure to hormones such as testosterone, and cannot be easily changed." (p.810) In addition, the above two authors state that attractive individuals typically receive greater compensation than the unattractive and are viewed as more intellectually competent, dominant, mentally healthy, intelligent, and socially skilled than unattractive people. (p.811)

Seating in American business culture will vary depending on who the business partner is, where the meeting is, and the nature of the meeting. For example, if it is a business partner whom you have worked with many times and hold a good, strong relationship, then naturally they are likely to sit and stand at a slightly closer distance. An arm's length or so away is enough to make them feel comfortable, without awkward too-far-apart distance. In general, matching the pace of the other with how they react to you when they sit, stand, or drink, is a good way to test how you could mirror that behavior to keep and good relationship. However, Beebe states that in Japan, the seating is a little different. In meeting rooms, the further seats from the door, the more respected people sit down in general. It's the 
same in taxi, when you are with your sempai or with your business partners, there are certain rules must be observed regarding where to sit according to their hierarchical ranks they perceive. In an elevator, kouhai often open doors for sempai and press the button for elevators. Usually the lower ranks sit or stand near the door so it is more convenient for them to do things for sempai. Also, studies show that when group members are seated in a circle, discussants are more likely to talk to the person across from them rather than to those on either side. Researchers have also found that more dominant group members tend to select a seat at the head of a rectangular table or a seat, which will maximize their opportunity to communicate with others because of increased immediacy cues. (Beebe, p. 18)

According to Beebe, eye contact has four functions: cognitive (when an individual's eyes provide an indication of his thought processes), monitoring (when individuals seeking for feedbacks or reactions), regulatory (to regulate the back and forth of a conversation and also to invite interaction) and lastly, expressive (to express attitude and emotions). (Beebe, p. 22) As the result, eyes contact takes a vital role in our nonverbal communication arena. According to my survey, it is important for Americans to look at people in the eyes during a conversation, especially during a business meeting where it requires close attention in order to gather information effectively. On the contrary, in Japanese culture, making eye contact is considered rude, because such behavior tends to create uncomfortableness or can be construed as a sign of aggression. The Japanese culture is a relatively non-eye-contact culture. Japanese public speakers are generally very afraid of looking at the audiences. (Satoshi, 1988) Therefore, when speaking to or approaching a Japanese individual, it is advised to make a very brief eye contact to signal the individual while also maintaining an appropriate eye level, such as the individual's neck.

A distinctive difference in the nonverbal communication is found in how the Japanese and American greet their business partners. In America, a simple introduction and a firm 
handshake are enough to start the meeting; however, in Japan, it is important to bow as a sign of respect to their business partners. The junior person bows first, lowest, and longest.

Historically, it is a sign of submission, the bow is a contemporary ritual that continues to convey respect and denote hierarchical status. (McDaniel, 1998) It is compulsory to present their Meishi or business card right after they introduce themselves at a meeting. According to one of my friends, a first year salary man at an advertising company in Japan, during the first week of training, he and his colleagues had to take classes about appropriate manners in a business setting including how to hand out business cards, how to bow, how to show their clients that they are listening in a conversation, etc. It is obvious that the Japanese business society has many strict rules when it comes to interacting with their clients or business partners. For instance, when a client hands you a business card, you must receive it with two hands then you read the card in front of them and make a comment about their business card. Afterwards, you put their card aside on the table next to you (most people line them up accordingly to their ranks) and go on with the meeting or the conversation. Once the meeting is over, you pick up the card and put it in your business card holder. When you hand them your business card at the beginning of a meeting, you present it using two hands while clearly introducing your name and the company you work for. While doing so, your name must face to the receiver. On the other hand, in the U.S., there is no particular rule when it comes to handing out business card. You simply just give your clients or business partners your card and go on with the meeting.

According to Blahova, the way the body is positioned sends out significant signals as it may reflect anxiety (looking down, hunching the shoulders), self-confidence (straight position, raised chin), hesitation (moving from one foot to another), etc. (Blahova, 2015). Therefore, it is important to learn about those things beforehand in order present yourself more positively. On the side note, another really interesting finding I have noticed along the 
way is how important body language is in a workplace between Japan vs the U.S. For instance, in the U.S., it is normal to show that you are tired or a little sleepy at work by stretching or yawning. However, yawning is considered rude and unacceptable during work in Japan. One of my friends was studying abroad at PSU, and saw a cashier yawn during work. She was so shocked; she mentioned to me that such a behavior in workplaces never happen in Japan because it is considered extremely rude and unprofessional.

\section{Conclusion}

As mentioned earlier, the communication process in business setting may influence the outcome of a business transaction. This tendency is more likely to occur in intercultural interactions in business setting involving Japanese business people and their U.S.

counterparts. Overall, the researcher believes that nonverbal elements in communication have an important role to play in daily life in both countries. Since most people do not pay much attention to nonverbal factors in their daily life interactions, it is important to learn more about them and the role they play in bringing about communication effectiveness. The results show a distinctive difference of the role nonverbal factors play in business settings between Japan and the U.S. The nonverbal factors present in the Japanese business communication process are complex and are deeply rooted in the historical evolution of Japanese culture while such factors present in the business communication process in the U.S. are far fewer and much simpler. Secondly, although the core notion of a business meeting of both countries is similar but Japanese business people generally pay a much closer attention to nonverbal details, compared to their American counterparts. The latter tends to be more relaxed and laid back, even during formal meetings. The reason for this difference seems deeply rooted in their cultural background of collectivism in Japan vs individualism in the U.S. In Japan, people tend to be keen on other's comfort and wellbeing rather than their own, especially when they are older or in higher social rank. Thus, this cultural norm tends to rely heavily on 
nonverbal communication cues. On the contrary, with the individualistic mindset dominating in American culture, such a tradition is considered extreme and is not practiced. The current study based on literature review and the survey reveals some distinct differences of nonverbal communication cues between Japan and the U.S., especially in the business setting such as facial expressions, body movement, spatial relationships, visual cues, vocal cues, and social relationship. In sum, by understanding these nonverbal differences that are deep-rooted in both cultures, we will be able to achieve communication effectiveness in intercultural communication process in all situations, including the business setting. 


\section{References}

Beebe, Steven. (1979, April 7). Nonverbal Communication in Business: Principles and Applications. Retrieved November 30, 2016.

Blahova, Maria. "Specific Role of Nonverbal Communication in Business | Blahova | European Scientific Journal, ESJ." N.p., n.d. Web. 17 Nov. 2016.

Bonaccio, Sylvia. O’reilly, Jane. Chiocchio, François. O’Sullivan, Sharon. (2016, July) Nonverbal Behavior and Communication in the Workplace: A Review and an Agenda for Research. Retrieved from http://journals.sagepub.com/doi/pdf/10.1177/0149206315621146

Chaney, Lillian. (2002). Intercultural Business Communication. Retrieved on October, 2017

Chu Yun, William Strong, and Jianyu Ma. (2005, July) "Silent Messages in Negotiations: The Role of Nonverbal Communication in Cross-cultural Business Negotiations." N.p., Web. 30 Nov. 2016.

Cooper, Ken. (1979, November). Nonverbal Communication for Business Success. Retrieved on October. 2017

Feigenbaum, Eric. Cultural Communication Differences in a Business. N.p., n.d. Web. 30 Nov. 2016.

Hooker, John. (2008, December). Cultural Differences in Business Communication. Retrieved from http://repository.cmu.edu/cgi/viewcontent.cgi?article=1149\&context=tepper

Japanese Nonverbal Communication. Dir. Thomas Seamster and Camila Hashbarger. The Center, 1978. DVD.

English, Donald E; Walker, Janet; Manton, Edgar J. (1999, January) "Business Communication Instructors' Perception of Nonverbal Communication." Web. 30 Nov. 2016.

Kobayashi, Sanae. (1996, December). Characteristics of Japanese Communication. Web. 30 Nov. 2016. 
Kopp, Rochelle. "Non-verbal Communication in Japanese Business." Non-verbal Communication in Japanese Business. N.p., 18 Mar. 2013. Web. 30 Nov. 2016.

Kudesia, Ravi. Elfenbein, Hillary. (2013, January). Nonverbal Communication in The Workplace. Retrieved from https://www.degruyter.com/downloadpdf/books/9783110238150/9783110238150.805/97831 10238150.805.pdf

Matsumoto, Michihiro. The Unspoken Way = Haragei: Silence in Japanese Business and Society. Tokyo: Kodansha International, 1988. Print.

Nakasako, Shun-itsu. "Japan." Association for Business Communication, Sept. 1998. Web. 30 Nov. 2016.

Potoker, Elaine S. (1993-Apr.)"ERIC - Management and Training across Cultures: Importance of Nonverbal Communication Strategies--A Case Study.N.p., n.d. Web. 17 Nov. 2016.

Sasaki, Ruth. Dickey, David. Aoki, Masaaki. (1999-2000) Communicating With Japanese in Business. Retrieved from https://www.jetro.go.jp/costarica/mercadeo/communicationwith.pdf

Victor, David. Limaye, Mohan. (1991, June 1st) Cross-Cultural Business Communication Research: State of the Art and Hypotheses for the 1990s. Retrieved from http://journals.sagepub.com/doi/pdf/10.1177/002194369102800306

Watman, John. (1984). Nonverbal Elements of International Business Communication. Retrieved on October, 2017

Zhou, Hui. Zhang Tingquin. (2009). Body Language in Business Negotiation. Retrieved from www.ccsenet.org/journal/index.php/ijbm/article/download/1680/1588 